\title{
Treatment with Lanreotide Depot Following Octreotide Long-Acting Release Among Patients with Gastroenteropancreatic Neuroendocrine Tumors
}

\author{
Muhammad Wasif Saif, ${ }^{1, *}$ Julie Fu, ${ }^{1}$ Melissa H. Smith, ${ }^{1}$ Barbara Weinstein, ${ }^{2}$ Valerie Relias, ${ }^{1}$ and Kevin P. Daly ${ }^{3}$
}

\begin{abstract}
Objective: To examine patients with metastatic gastroenteropancreatic neuroendocrine tumors (GEP-NETs) who receive sequential treatment with somatostatin analogs.

Materials and Methods: This retrospective chart review examined lanreotide depot/autogel tolerability and efficacy among GEP-NET patients who received lanreotide after octreotide long-acting release (LAR) at Tufts University Medical Center. Information obtained included background patient characteristics, dosing, adverse events (AEs), radiologic response, and biochemical markers.

Results: Patients ( $n=16$; 43-81 years; mean age, 64.25 years; 11 female) with nonfunctional, low-grade GEP-NETs receiving octreotide LAR 30-60 mg were transitioned to lanreotide because of patient decision $(n=6)$, disease progression $(n=6)$, AEs $(n=2)$, poor tolerance $(n=1)$, and injection discomfort/pain $(n=1)$. Lanreotide doses started at $120 \mathrm{mg}(n=13), 90 \mathrm{mg}(n=1)$, or $60 \mathrm{mg}(n=2) ; 8$ patients received concomitant therapies, mostly liver-directed (radiofrequency ablation/radioembolization). AEs associated with lanreotide experienced by $\geq 2$ patients were fatigue, diarrhea, nausea, hypertension, pancreatic enzyme deficiency, and hyperglycemia. Radiologic treatment responses of the combination of lanreotide with other therapeutic modalities included complete response $(n=1)$, partial response $(n=5)$, and stable disease $(n=9)$. One patient had radiologic progression. Serum serotonin and chromogranin levels decreased, but urinary 5-hydroxyindoleacetic acid levels appeared relatively unchanged.
\end{abstract}

Conclusion: Among post-octreotide GEP-NET patients, including those with disease progression or poor octreotide tolerance, lanreotide alone or with concomitant therapies was well tolerated and associated with radiologic responses.

Keywords: chromogranin; gastroenteropancreatic neuroendocrine tumors; lanreotide depot; octreotide longacting release

\section{Introduction}

The incidence of neuroendocrine tumors (NETs) has increased markedly in the United States over the past several decades. The U.S. Surveillance, Epidemiology, and End Results (SEER) database, for example, shows a 6.4-fold increase in NETs from 1973 to 2012 (1.096.98 per 100,000 persons). ${ }^{1}$ For gastroenteropancreatic neuroendocrine tumors (GEP-NETs), the overall incidence was 3.56 per 100,000 persons between 2000 and 2012. Across all NET patients, median overall survival was the highest for NETs in the appendix ( $>30$ years) and rectum (24.6 years), while NETs in the pancreas showed the lowest median survival (3.6 years). ${ }^{1}$ 
Evaluation of somatostatin receptor expression in human tissues is complicated by the fact that there are five receptor subtypes (SSTR1-SSTR5). ${ }^{2}$ Only a limited number of studies have comprehensively investigated the expression of all five of the SSTR subtypes, and thus knowledge regarding the correlation of their expression with clinical outcomes in NET is incomplete. ${ }^{3}$

An assessment of SSTR receptor subtypes in NETs revealed that $51 \%$ of cases highly expressed SSTR2, $47 \%$ SSTR1, $43 \%$ SSTR5, 36\% SSTR4, and 23\% SSTR3. ${ }^{3}$ A high expression of both SSTR1 and SSTR2 was found more frequently in pancreatic NETs and small intestinal NETs than in other NETs. ${ }^{3}$ It is important to note that octreotide and lanreotide, both of which are synthetic somatostatin analogs (SSAs), primarily bind to SSTR2 and SSTR.$^{3}$

The randomized, double-blind, placebo-controlled Controlled Study of Lanreotide Antiproliferative Response in Neuroendocrine Tumors (CLARINET) was the largest trial and one of the few trials conducted to compare long-acting lanreotide depot/autogel $(n=101$, hereafter referred to as lanreotide) with placebo $(n=103)$ among patients with primary NETs in the pancreas, midgut, or hindgut. ${ }^{4}$ Progression-free survival (PFS) was the primary efficacy end-point of CLARINET. There was significantly prolonged PFS among patients treated with lanreotide (median PFS not reached vs. 18.0 months; $p<0.001$; hazard ratio for progression/death for lanreotide vs. placebo, $0.47 ; 95 \%$ confidence interval [CI], $0.30-0.73) .{ }^{4}$ The estimated rates of PFS at 24 months were $65.1 \%$ (95\% CI, 54.0-74.1) versus 33.0\% (95\% CI, 23.0-43.3) for the lanreotide and placebo groups, respectively. A greater number of patients in the placebo group $(n=58)$ than the lanreotide group $(n=30)$ had centrally assessed disease progression events. Two patients from each of the groups died. The most commonly reported treatment-related adverse events (AEs; $>10 \%$ of patients) were diarrhea ( $26 \%$ in lanreotide group and $9 \%$ in placebo group) and abdominal pain (14\% in lanreotide group and $2 \%$ in placebo group). A follow-up of CLARINET published 2 years later further demonstrated the long-term safety and tolerability of lanreotide. $^{5}$

The treatment goals of NETs include suppressing tumor growth and controlling the symptoms of carcinoid syndrome. ${ }^{6}$ The primary objective of the Evaluating Lanreotide Efficacy and Safety as a Carcinoid-syndrome Treatment (ELECT) study was to determine whether there was a clinically meaningful difference between lanreotide $(n=59)$ and placebo $(n=56)$ groups in the use of daily short-acting subcutaneous rescue octreotide as a correlate of improved symptom control. ${ }^{6}$ Inclusion criteria were carcinoid (neuroendocrine) tumor or one on an unknown location with liver metastasis and a history of carcinoid syndrome. The adjusted mean (95\% CI) percentage of days of rescue octreotide use during the 16-week double-blind phase was significantly lower in the lanreotide group (33.7\% [25.0-42.4]) than the placebo group (48.5\% [39.6-57.4]), with a betweengroup absolute difference of $-14.8 \%$ (95\% CI, -26.8 to $-2.8 ; p=0.017$ ). From baseline to week 12, global health status/quality of life, gastrointestinal symptoms, and endocrine symptoms all improved among lanreotidetreated patients, while the placebo group experienced lesser improvements or no changes $(95 \%$ CIs for adjusted treatment differences were wide and favored the lanreotide group). Excluding diarrhea and flushing, which were assessed separately in this study, no AE occurred in $>9 \%$ of patients, and few AEs were serious $(n=2$ [3.4\%] for lanreotide vs. $n=5$ [8.8\%] for placebo). ${ }^{6}$ These results indicate that treatment with lanreotide could reduce the number of days that treatment with rescue octreotide is required.

Despite the fact that primary treatment for metastatic NETs often includes SSAs, ${ }^{7,8}$ the tolerability of sequential use of SSAs for GEP-NETs, including octreotide followed by lanreotide, has not been studied in depth. Although octreotide is not approved by the U.S. Food and Drug Administration (FDA) for treatment of GEP-NETs, ${ }^{9}$ a few studies have been conducted to measure the safety and efficacy of treatment for NETs. One of these was a randomized, placebo-controlled study that included patients with metastatic midgut NETs. The results showed that octreotide long-acting release (LAR; $n=42$ ) stabilized tumor growth, prolonged time to tumor progression, and improved long-term survival compared with placebo $(n=43) .^{10}$

Lanreotide $120 \mathrm{mg}$ administered as a deep subcutaneous injection is approved by the FDA for treatment of GEP-NETs in patients with unresectable, well- or moderately-differentiated, locally-advanced, or metastatic GEP-NETs to improve PFS. ${ }^{11}$ Recently (September 2017), the same dosage was approved by the FDA for the treatment of carcinoid syndrome in adults to reduce the frequency of short-acting SSA rescue therapy. ${ }^{11}$ The objectives of this case series included assessing the safety, tolerability, and efficacy of lanreotide in patients with various GEP-NETs who were previously treated with octreotide LAR. 


\section{Materials and Methods}

Study design

Institutional Review Board (IRB) approval was granted before the initiation of this retrospective chart review that was conducted at the Tufts University Medical Center. The procedures followed in this study were in accordance with the ethical standards of the responsible committee on human experimentation (institutional and national) and with the Declaration of Helsinki. Included patients had NETs and received lanreotide following octreotide LAR.

Each patient was evaluated by an oncologist or their nurse every 4 weeks before receiving subsequent lanreotide injections. All patients received deep subcutaneous injections of lanreotide, with the exception of one individual who received one injection of lanreotide by intramuscular route.

\section{Assessments and outcome measures}

The information obtained from patient charts included demographic data, tumor stage/grade, SSA treatment/ dose, AEs, radiologic response, and baseline/current levels of biochemical markers (chromogranin A [CgA], urinary 5-hydroxyindoleacetic acid [5-HIAA; primary metabolite of serotonin], serotonin, gastrin, pancreatic polypeptide, and adrenocorticotropic hormone). Treatment response, assessed radiologically, was defined as complete response (CR), partial response (PR), stable disease $(\mathrm{SD})$, and disease control rate $(\mathrm{CR}+\mathrm{PR}+\mathrm{SD}) .{ }^{12-14}$

Radiologic imaging, including computed tomography scans of the abdomen, pelvis, and chest, were performed every 3 months, and patients who underwent liver-directed therapy also received dedicated magnetic resonance imaging (MRI) along with an additional MRI scan within 8-12 weeks of the procedure. An octreotide scan was performed only at baseline and 6-12 months later to confirm disease progression and/or response. Serologic tumor markers were evaluated at each visit, and 5-HIAA was collected in 24-h urine samples every 3-6 months.

\section{Results}

Patient characteristics

A total of 16 patients (11 female, 5 male; age range, $43-$ 81 years; mean age, 64.3 years) with nonfunctional and low-grade NETs were included in this retrospective chart review (Table 1). The primary tumor locations are presented in Table 1 and included 9 intestinal, 4 pancreatic, and 3 unknown. The locations of metastatic sites, along with stage (all of which are III or IV) and histology, are also presented in Table 1. Each of the 16 patients had been receiving octreotide LAR 30$60 \mathrm{mg}$ for a median duration of 6.5 months (range 336 months) and were transitioned to lanreotide because of patient decision $(n=6)$, disease progression $(n=6)$, AEs $(n=2)$, poor tolerance $(n=1)$, and injection discomfort/pain ( $n=1$; Table 2$)$. The starting doses of lanreotide were $120 \mathrm{mg}(n=13), 90 \mathrm{mg}(n=1)$, or $60 \mathrm{mg}$ $(n=2)$ every 28 days, based on renal dysfunction. At the time the results reported here were quantified, the median number of lanreotide cycles was 5.23 (range 210); however, all but 1 patient is still receiving lanreotide. Concomitant therapies were noted in 8 of 16 patients, including radiofrequency ablation $(n=3)$, yttrium-90 transarterial radioembolization ( $\mathrm{Y}^{90}$ TARE; $n=1$ ), chemotherapy $(n=1)$, surgery $(n=1)$, chemotherapy $+\mathrm{Y}^{90}$ TARE $(n=1)$, and chemotherapy+surgery $(n=1$; Table 3$)$.

\section{Adverse events}

During the observation period, AEs affected 11 of the patients; gastrointestinal AEs (diarrhea, nausea, constipation, and abdominal pain) were the most common $(n=6)$ and were considered to be associated with lanreotide (Table 4). Other AEs experienced by more than 1 individual included fatigue $(n=3)$, hypertension $(n=2)$, hyperglycemia $(n=2)$, and pancreatic exocrine enzyme deficiency $(n=2)$.

\section{Tumor response}

Radiologic treatment responses of the combination of lanreotide with other therapeutic modalities were CR $(n=1), \mathrm{PR}(n=5)$, or progressive disease $(n=1)$. Overall disease control (a combination of $\mathrm{CR}+\mathrm{PR}+\mathrm{SD}$ ) was achieved in 15 of 16 patients $(93.8 \%)$ at the end of the study. Five patients achieved PR; however, it is important to note that all of these patents also received concomitant liver-directed treatment: radiofrequency ablation (RFA) in 3 patients and $\mathrm{Y}^{90}$ TARE in 2 patients. One patient had no evidence of disease after surgical resection (CR). In addition to these patients, 9 others still had $\mathrm{SD}$ at the end of the study period.

\section{Biochemical response}

Numerical decreases in CgA levels after initiation of lanreotide treatment were observed in 15 of 16 patients (range of CgA levels changed from 7-2555 nmol/L at baseline to $<5-440 \mathrm{nmol} / \mathrm{L}$ after treatment; Table 3). Urinary 5-HIAA values, available for 7 patients, ranged from $17.3-120.3 \mu \mathrm{mol} /$ day at baseline to $16.2-83.7 \mu \mathrm{mol} /$ day after treatment. Serum serotonin ranged from 
Table 1. Baseline and Demographic Information $(N=16)$

\begin{tabular}{|c|c|c|c|c|c|c|c|c|}
\hline Patient & $\begin{array}{l}\text { Gender/age } \\
\text { (years) }\end{array}$ & Primary tumor location & Metastatic site(s) & Grade & $\begin{array}{l}\text { Stage } \\
\text { (I-IV) }\end{array}$ & Histology ${ }^{a}$ & $\begin{array}{l}\text { Mitotic index } \\
\quad(10 \mathrm{HPF})\end{array}$ & $\begin{array}{c}\mathrm{Ki}-67 \\
(\%)\end{array}$ \\
\hline 1 & $M, 81$ & Duodenum & Liver, mesentery & G1 & IV & Well-differentiated NET & $<2$ & 3 \\
\hline 2 & $\mathrm{~F}, 68$ & Antrum of stomach & $\mathrm{N} / \mathrm{A}$ & G1 & III & Well-differentiated NET & $<2$ & 5 \\
\hline 3 & M, 69 & Ileocecum & Right inguinal LN, liver & G2 & IV & $\begin{array}{l}\text { Moderately-differentiated, } \\
\text { intermediate-grade NET }\end{array}$ & $8-10$ & $3-4$ \\
\hline 4 & $M, 81$ & $\begin{array}{l}\text { Mesenteric mass } \\
\quad \text { (primary unknown) }\end{array}$ & Abdominal LN & G1 & III & $\begin{array}{l}\text { Well-differentiated NET, } \\
\text { positive } \\
\text { immunohistochemical } \\
\text { stains for synaptophysin, } \\
\text { chromogranin-A, } \\
\text { serotonin, and negative } \\
\text { for TTF-1 }\end{array}$ & $<2$ & 7 \\
\hline 5 & $F, 72$ & lleum & LN, liver & G2 & IV & $\begin{array}{l}\text { Well- to moderately- } \\
\text { differentiated NET }\end{array}$ & 10 & $<10$ \\
\hline 6 & $F, 56$ & Unknown & Liver & G1 & IV & $\begin{array}{l}\text { Well-differentiated NET, } \\
\text { positive } \\
\text { immunohistochemical } \\
\text { stains for synaptophysin, } \\
\text { chromogranin-A, and } \\
\text { negative for TTF-1, CK7, } \\
\text { CK20, CDX2 }\end{array}$ & $6-8$ & 8 \\
\hline 7 & $\mathrm{~F}, 75$ & $\begin{array}{l}\text { Mediastinal LN } \\
\quad \text { (primary unknown) }\end{array}$ & Hilar LN & G2 & IV & $\begin{array}{l}\text { Moderately-differentiated } \\
\text { NET, positive } \\
\text { immunohistochemical } \\
\text { stains for synaptophysin, } \\
\text { chromogranin-A, } \\
\text { serotonin, and negative } \\
\text { for TTF-1, CK7, VIP, S-100, } \\
\text { CK20, CDX2, CK5/6, p63, } \\
\text { napsin-A }\end{array}$ & $14-15$ & 26 \\
\hline 8 & M, 78 & Pancreas & Liver, spleen & G2 & IV & $\begin{array}{l}\text { Moderately-differentiated } \\
\text { NET }\end{array}$ & $5-6$ & 15 \\
\hline 9 & $F, 60$ & Ileocecal & Liver & G2 & IV & $\begin{array}{l}\text { Moderately-differentiated } \\
\text { NET }\end{array}$ & 8 & 16 \\
\hline 10 & $F, 53$ & Pancreas & Liver & G1 & IV & $\begin{array}{l}\text { ACTH-producing pancreatic } \\
\text { NET complicated by } \\
\text { Cushing's syndrome }\end{array}$ & 8 & $\mathrm{~N} / \mathrm{A}$ \\
\hline 11 & $F, 64$ & Gastric & Liver, spleen, bone, lung & G2 & IV & $\begin{array}{l}\text { Moderately-differentiated } \\
\text { NET }\end{array}$ & 4 & 10 \\
\hline 12 & $F, 61$ & Pancreas & Peritoneum & G1 & IV & Well-differentiated NET & 1 & $\mathrm{~N} / \mathrm{A}$ \\
\hline 13 & M, 47 & Ileum & Liver, colon & G1-G2 & IV & $\begin{array}{l}\text { Well- to moderately- } \\
\text { differentiated NET }\end{array}$ & 12 & 16 \\
\hline 14 & $F, 43$ & Gastric & Liver & G2 & IV & $\begin{array}{l}\text { Moderately-differentiated } \\
\text { NET }\end{array}$ & 3 & 3 \\
\hline 15 & $F, 56$ & Pancreas & Liver, LN & $\mathrm{G} 1-\mathrm{G} 2$ & IV & $\begin{array}{l}\text { Well- to moderately- } \\
\text { differentiated NET }\end{array}$ & 6 & 13 \\
\hline 16 & $F, 64$ & Appendix & Peritoneum, LN & G2 & IV & $\begin{array}{l}\text { Moderately-differentiated } \\
\text { NET }\end{array}$ & $<2$ & 4 \\
\hline
\end{tabular}

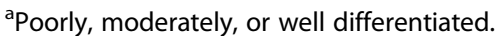

ACTH, adrenocorticotropic hormone; CDX2, caudal-type home box transcription factor 2; CK, cytokeratin; G, grade; HPF, high-power field; LN, lymph nodes; N/A, not assessed; NET, neuroendocrine tumor; TTF-1, thyroid transcription factor-1; VIP, vasoactive intestinal peptide.

$<56.8-7320.8 \mathrm{nmol} / \mathrm{L}$ at baseline to $<56.8-3024.8$ $\mathrm{nmol} / \mathrm{L}$ following initiation of lanreotide. Decreases in other serologic markers were noted in 4 patients, including gastrin $(n=2)$, pancreatic polypeptide $(n=1)$, and pancreatic polypeptide and adrenocorticotropic hormone $(n=1)$.

\section{Discussion}

This retrospective analysis reports the safety, tolerability, and efficacy of lanreotide in patients with various
GEP-NETs who were previously treated with octreotide LAR. Lanreotide was well tolerated among these patients, including those who experienced disease progression or lack of tolerance on octreotide LAR. As a part of multidisciplinary management of these patents, many of them received concomitant treatment with other modalities, especially liver-directed therapy. Overall disease control (a combination of $\mathrm{CR}+\mathrm{PR}+\mathrm{SD}$ ) was $>90 \%$ in our study, including CR in $6 \%, \mathrm{PR}$ in $31 \%$, and SD in $56 \%$. One patient had no evidence of disease 
Table 2. Octreotide to Lanreotide Depot: Rationale and Dosing

\begin{tabular}{|c|c|c|c|c|}
\hline Patient & $\begin{array}{l}\text { Last octreotide } \\
\text { dose (mg IM) }\end{array}$ & Reason for transitioning to lanreotide & $\begin{array}{c}\text { Lanreotide } \\
\text { starting/current } \\
\text { dose (mg SQ) }\end{array}$ & $\begin{array}{c}\text { Total lanreotide } \\
\text { doses }\end{array}$ \\
\hline 1 & 30 & Patient decision & 120 & 9 \\
\hline 2 & 30 & Patient decision & 120 & 5 \\
\hline 3 & 30 & Patient decision & 120 & 8 \\
\hline 4 & 30 & Patient decision & $60^{\mathrm{a}}$ & 8 \\
\hline 5 & 30 to $>40$ & Increased serologic marker+new liver lesion & 120 & 8 \\
\hline 6 & 30 & Patient decision & 120 & $3^{b}$ \\
\hline 7 & 40 & Diarrhea and abdominal pain & 120 & 2 (stopped) $^{c}$ \\
\hline 8 & 30 to $>40$ & Progressive disease (liver) & 120 & 3 \\
\hline $9^{d}$ & 20 & Cost, Gl pain, nausea & 120 & 10 \\
\hline 10 & 20 & Radiologic and serologic disease progression & $90^{\mathrm{a}}$ & 5 \\
\hline 11 & 30 to $>60$ & GI upset, bone progression (stable liver) & 120 & 3 \\
\hline 12 & 40 & Serologic marker & 120 & 3 \\
\hline 13 & 20 to $>40$ & Patient decision & 120 & 5 \\
\hline 14 & 30 & Intolerance, low muscle mass (anorexia) & 120 & 3 \\
\hline 15 & Unknown & Serologic progression & 120 & 3 \\
\hline 16 & 30 & Buttock pain & $60^{\mathrm{a}}$ & 6 \\
\hline
\end{tabular}

aPatients No. 4 and No. 10 were successfully escalated to full dose without any adverse events, and patient No. 16 had dose escalated to 90 mg but not beyond because kidney function remained moderately impaired due to diabetic nephropathy.

${ }^{b}$ Past intolerance to octreotide-associated diarrhea.

'Patient received 1 dose at Roswell Park Cancer Center (Buffalo, NY) and an unknown number of additional doses administrated by a healthcare professional located closer to the patient's residence.

${ }^{\mathrm{d}}$ Received 1 inadvertent misadministration of lanreotide depot by IM route instead of SQ route.

$\mathrm{Gl}$, gastrointestinal; IM, intramuscular, SQ, subcutaneous.

after surgical resection (CR), while the patients with PR had received concurrent liver-directed therapy as described in the Results section. In 2016, Phan et al. reported on tumor response in the CLARINET study of lanreotide depot versus placebo in patients with metastatic GEP-NETs. Among 110 patients who were on the lanreotide arm, 2 patients achieved a PR and 65 demonstrated SD (44/103 patients receiving placebo). ${ }^{15}$

The most common AEs reported in these patients were consistent with those reported in previous studies of lanreotide. ${ }^{4,5}$ These results also noted the use of lanreotide in a patient with moderate renal dysfunction. In this patient, lanreotide was started at $60 \mathrm{mg}$ and was titrated up to a maximum tolerated dose of $90 \mathrm{mg}$. This is noteworthy because dose adjustments of lanreotide depot for moderate renal impairment are currently only recommended for acromegaly patients. ${ }^{11}$

The outcomes of this study also demonstrated best tumor response of $\mathrm{SD}, \mathrm{PR}$, or CR in all but 1 patient during lanreotide treatment. Of note is that this case series included a small number of patients with GEP-NETs, which is a limitation, as is the retrospective nature of the analysis. Also, half of the patients $(8 / 16)$ were receiving concomitant therapies, mostly liver-directed therapies, including radiofrequency ablation and transarterial radioembolization. Several patients received concomitant chemotherapy. Among these patients, gastrointestinal AEs, including diarrhea, were either absent or reported as low grade despite receiving concomitant chemotherapy containing capecitabine or irinotecan, 2 of the well-known systemic cytotoxic agents associated with dose-limiting toxicities, including diarrhea.

Following sequencing from octreotide to lanreotide, reductions in the levels of CgA were observed in 15 of 16 patients, with the most substantial reductions occurring among those who had the greatest levels before treatment with lanreotide. Currently, CgA, which can be identified in patients with GEP-NETs by immunohistochemistry, is widely used as a neuroendocrine marker, especially among patients with well-differentiated NETs. ${ }^{16-18}$ Despite its utility, the use of CgA has some limitations, including a lack of international standardization. ${ }^{16}$ In addition, recent research has raised a question of whether $\mathrm{CgA}$ acts more effectively as a diagnostic biomarker than as a method for identifying the risk of metastasis. ${ }^{17}$ However, the results of a pharmacokinetic /pharmacodynamics model analysis using CLARINET data suggest that change in CgA over time is a relevant covariate/predictor of PFS in GEP-NETs among patients who are either untreated or treatment-naive ${ }^{18}$; similar findings have been reported elsewhere. ${ }^{12}$

The efficacy of utilizing 5-HIAA as a prognostic marker among individuals with GEP-NETs has not been definitively established. Several studies have concluded that increased levels of urinary 5-HIAA can be associated with decreases in survival. ${ }^{19,20}$ However, a 
Table 3. Biomarkers, Concurrent Treatments, Radiologic Response, and Serologic Markers

\begin{tabular}{|c|c|c|c|c|c|c|c|}
\hline Patient & & $\underset{(\mathrm{nmol} / \mathrm{L})}{\mathrm{CgA}^{\mathrm{a}}}$ & $\begin{array}{c}\text { 5-HIAA }{ }^{\mathrm{b}} \\
(\mu \mathrm{mol} / \mathrm{day})\end{array}$ & $\begin{array}{c}5-\mathrm{HT}^{\mathrm{c}} \\
(\mathrm{nmol} / \mathrm{L})\end{array}$ & $\begin{array}{c}\text { Required } \\
\text { concurrent treatment? }\end{array}$ & $\begin{array}{l}\text { Radiologic } \\
\text { response }\end{array}$ & Other serologic markers \\
\hline 1 & Level at lanreotide initiation & 30 & $\mathrm{~N} / \mathrm{A}$ & 431.3 & No & SD & $\begin{array}{l}\text { Gastrin level reduced } \\
(<100 \mathrm{ng} / \mathrm{L})^{d}\end{array}$ \\
\hline Current & 39 & $\mathrm{~N} / \mathrm{A}$ & 448.3 & & & & \\
\hline 2 & Level at lanreotide initiation & 43 & $\mathrm{~N} / \mathrm{A}$ & $\mathrm{N} / \mathrm{A}$ & No & SD & $\begin{array}{l}\text { Gastrin level reduced } \\
\qquad(239-76 \mathrm{ng} / \mathrm{L})^{d}\end{array}$ \\
\hline Current & 15 & $\mathrm{~N} / \mathrm{A}$ & $\mathrm{N} / \mathrm{A}$ & & & & \\
\hline $\begin{array}{l}3 \\
\text { Current }\end{array}$ & $\begin{array}{l}\text { Level at lanreotide initiation } \\
\qquad<5\end{array}$ & $7^{7} / \mathrm{A}$ & $\begin{array}{c}\mathrm{N} / \mathrm{A} \\
1509.6\end{array}$ & 2116.8 & RFA & PR & None \\
\hline $\begin{array}{l}4 \\
\text { Current }\end{array}$ & $\begin{array}{l}\text { Level at lanreotide initiation } \\
\qquad 112\end{array}$ & $\begin{array}{l}224 \\
N / A\end{array}$ & $\begin{array}{r}\mathrm{N} / \mathrm{A} \\
584.5\end{array}$ & 2451.6 & No & SD & None \\
\hline $\begin{array}{l}5 \\
\text { Current }\end{array}$ & $\begin{array}{l}\text { Level at lanreotide initiation } \\
\qquad 14\end{array}$ & $\begin{array}{l}18 \\
18.8\end{array}$ & $\begin{array}{l}25.1 \\
3024.8\end{array}$ & 3893.1 & $\mathrm{Y}^{90}$ TARE & PR & None \\
\hline $\begin{array}{l}6 \\
\text { Current }\end{array}$ & $\begin{array}{l}\text { Level at lanreotide initiation } \\
\qquad 224\end{array}$ & $\begin{array}{l}366 \\
20.4\end{array}$ & $\begin{array}{l}29.8 \\
402.9\end{array}$ & 505.1 & No & SD & None \\
\hline $\begin{array}{l}7 \\
\text { Current }\end{array}$ & $\begin{array}{l}\text { Level at lanreotide initiation } \\
\qquad 122\end{array}$ & $\begin{array}{l}168 \\
N / A\end{array}$ & $\begin{array}{r}\mathrm{N} / \mathrm{A} \\
<56.8\end{array}$ & $<56.8$ & No & SD & None \\
\hline $\begin{array}{l}8 \\
\text { Current }\end{array}$ & $\begin{array}{l}\text { Level at lanreotide initiation } \\
204\end{array}$ & $\begin{array}{l}2555 \\
\mathrm{~N} / \mathrm{A}\end{array}$ & $\begin{array}{r}\mathrm{N} / \mathrm{A} \\
505.1\end{array}$ & 3961.2 & CAPTEM and $Y^{90}$ TARE & PR & None \\
\hline $\begin{array}{l}9 \\
\text { Current }\end{array}$ & $\begin{array}{l}\text { Level at lanreotide initiation } \\
\qquad 29\end{array}$ & $\begin{array}{l}172 \\
\mathrm{~N} / \mathrm{A}\end{array}$ & $\begin{array}{r}\mathrm{N} / \mathrm{A} \\
431.3\end{array}$ & 317.8 & Debulking surgery & SD & None \\
\hline 10 & Level at lanreotide initiation & 30 & $\mathrm{~N} / \mathrm{A}$ & 1163.4 & No & SD & $\begin{array}{l}\text { ACTH-producing tumor } \\
\text { normalized; PPP reduced } \\
\text { by } 50 \%(1221-610 \mathrm{ng} / \mathrm{L})^{\mathrm{e}}\end{array}$ \\
\hline Current & $<5$ & $\mathrm{~N} / \mathrm{A}$ & 1140.7 & & & & \\
\hline $\begin{array}{l}11 \\
\text { Current }\end{array}$ & $\begin{array}{l}\text { Level at lanreotide initiation } \\
160\end{array}$ & $\begin{array}{l}382 \\
16.2\end{array}$ & $\begin{array}{l}45.5 \\
1957.9\end{array}$ & 4523.0 & CAPTEM, sunitinib & PD & None \\
\hline 12 & Level at lanreotide initiation & 67 & N/A & 1004.5 & $\begin{array}{l}\text { 5-FU, irinotecan, } \\
\text { debulking surgery }\end{array}$ & CR & $\begin{array}{l}\text { PPP reduced by }>50 \% \\
(1100-430 \mathrm{ng} / \mathrm{L})^{\mathrm{e}}\end{array}$ \\
\hline Current & $>5$ & $\mathrm{~N} / \mathrm{A}$ & 862.6 & & & & \\
\hline $\begin{array}{l}13 \\
\text { Current }\end{array}$ & $\begin{array}{l}\text { Level at lanreotide initiation } \\
\qquad>5\end{array}$ & $\begin{array}{l}93 \\
21.4\end{array}$ & $\begin{array}{l}36.1 \\
1163.4\end{array}$ & 7320.8 & RFA & $P R$ & None \\
\hline $\begin{array}{l}14 \\
\text { Current }\end{array}$ & $\begin{array}{l}\text { Level at lanreotide initiation } \\
18\end{array}$ & $\begin{array}{l}21 \\
66.9\end{array}$ & $\begin{array}{l}17.3 \\
164.6\end{array}$ & 3637.7 & RFA & PR & None \\
\hline $\begin{array}{l}15 \\
\text { Current }\end{array}$ & $\begin{array}{l}\text { Level at lanreotide initiation } \\
\qquad 440\end{array}$ & $\begin{array}{l}735 \\
83.7\end{array}$ & $\begin{array}{l}120.3 \\
187.3\end{array}$ & 317.8 & No & SD & None \\
\hline $\begin{array}{l}16 \\
\text { Current }\end{array}$ & $\begin{array}{l}\text { Level at lanreotide initiation } \\
78\end{array}$ & $\begin{array}{l}382 \\
N / A\end{array}$ & $\begin{array}{l}\mathrm{N} / \mathrm{A} \\
38.6\end{array}$ & 1339.3 & No & SD & None \\
\hline
\end{tabular}

${ }^{\mathrm{a}} \mathrm{CgA}$ target level, $0-5.0 \mathrm{nmol} / \mathrm{L}$.

${ }^{b_{5}-\text { HIAA target level, } 0-77.9 \mu \mathrm{mol} / \text { day. }}$

${ }^{{ }^{2}} 5$-HT target level, $119.2-1821.7 \mathrm{nmol} / \mathrm{L}$.

dGastrin normal range, $0-100 \mathrm{ng} / \mathrm{L}$.

ePPP normal range, 70-430 $\mathrm{ng} / \mathrm{L}$.

5-FU, 5-fluorouracil; 5-HIAA, 5-hydroxyindoleacetic acid; 5-HT, serotonin; CAPTEM, capecitabine+temozolomide; CgA, chromogranin A; CR, complete response; G1, grade 1; PD, progressive disease; PPP, pancreatic polypeptide; PR, partial response; RFA, radiofrequency ablation; SD, stable disease; TARE, transarterial radioembolization; $Y^{90}$, yttrium- 90 .

multivariate analysis published in 2016 indicated that there is no prognostic value for 5 -HIAA. ${ }^{21}$ These confounding results clearly indicate that additional research regarding prognostic markers is still needed.

The prescribing information of lanreotide produced in 2014 includes renal dose adjustments for acromegaly, ${ }^{11}$ which should be considered when treating patients. Specifically, acromegaly patients with moderate to severe renal impairment should receive an initial dose of $60 \mathrm{mg}$ by deep subcutaneous injection every 4 weeks for 3 months, followed by dose adjustments, as described for non-renal-impaired patients. It is stated that caution should be used when considering an extended dosing interval for acromegaly, including $120 \mathrm{mg}$ every 6 or 8 weeks, among patients with moderate or severe renal impairment. However, no dose adjustments are recommended for mild to moderate renal impairment in patients with GEP-NETs, and currently there are no data available for dosing recommendations in GEP-NET patients with severe renal impairment. 
Table 4. Adverse Events

\begin{aligned} & \hline Patient \multicolumn{1}{c}{ Adverse events/grade (CTCAEv4.0) } \\ & \hline 1 G1 fatigue \\ & 2 None \\ & 3 G2 hypertension \\ & 4 None \\ & 5 G2 pancreatic exocrine enzyme deficiency, G1 weight loss ${ }^{\mathrm{a}}$, \\ & G1 headache \\ & 6 None \\ & 7 G1 tremor, G2 hyperglycemia, G1 fatigue, G2 nausea, \\ & G1 blurred vision \\ & 8 G1 nausea, G1 abdominal pain \\ & 9 G1 diarrhea, G1 hypertension \\ & 10 None \\ & 11 G1 diarrhea \\ & 12 None \\ & 13 G1 diarrhea, G2 pancreatic exocrine enzyme deficiency, \\ & G3 hyperglycemia \\ & 14 G1 pruritus (no rash) \\ & 15 G1 fatigue \\ & 16 G1 constipation, G1 alopecia \\ & \hline\end{aligned}

a Possibly related to pancreatic exocrine enzyme deficiency.

CTCAEv.4.0, Common Terminology Criteria for Adverse Events, version 4.0; G, grade 1 .

Additional studies not only provide information pertaining to severe renal impairment but also help define efficacy and safety in patients who were previously treated with octreotide or another SSA. We are currently conducting a retrospective medical chart review that is designed to include data obtained from $\sim 100 \mathrm{pa}-$ tients (ClinicalTrials.gov number NCT03112694). The objectives of that retrospective analysis include evaluating the efficacy and safety of lanreotide in a real-world setting, providing additional information on lanreotide efficacy and safety following treatment with octreotide, assessing both quality of life and patient satisfaction, and identifying the reasons why patients transitioned from octreotide to lanreotide.

In summary, treatment with lanreotide was well tolerated among patients with GEP-NETs when given alone or in combination with other treatment modalities, including radioembolization, radiofrequency ablation, and chemotherapy. Dose escalation was also well tolerated in a patient with moderate renal dysfunction. To our knowledge, results from this retrospective analysis also documented for the first time a clinical, biochemical, and radiological benefit of transitioning patients with GEP-NETs from one SSA (octreotide LAR) to another (lanreotide).

\section{Acknowledgments}

IRB approval for this study was provided by the Tufts University Medical Center, and data were acquired, analyzed, and interpreted by the authors, who are all em- ployees of the Tufts Medical Center. The authors thank Sarah Mizne, PharmD, and Aric Fader, PhD, of MedVal Scientific Information Services, LLC, for medical writing and editorial assistance. This article was prepared according to the International Society for Medical Publication Professionals' "Good Publication Practice for Communicating Company-Sponsored Medical Research: The GPP3 Guidelines" and the International Committee of Medical Journal Editors' "Uniform Requirements for Manuscripts Submitted to Biomedical Journals."

\section{Funding}

Ipsen Biopharmaceuticals, Inc. provided support for editorial assistance to MedVal Scientific Information Services, LLC. Aside from procuring editorial support, Ipsen did not contribute to the study conduct or reporting of results. The authors retain full responsibility for the concept, analysis, and all content in the final version for submission.

\section{Author Disclosure Statement}

M.W.S.: speakers' bureau, Ipsen Biopharmaceuticals; research funding, Ipsen Biopharmaceuticals. J.F., M.H.S., B.W., and K.P.D.: nothing to disclose. V.R.: speakers' bureau, AbbVie, Genentech.

\section{References}

1. Dasari A, Shen C, Halperin D, et al. Trends in the incidence, prevalence, and survival outcomes in patients with neuroendocrine tumors in the United States. JAMA Oncol. 2017;3:1335-1342.

2. Reubi JC, Schonbrunn A. Illuminating somatostatin analog action at neuroendocrine tumor receptors. Trends Pharmacol Sci. 2013;34:676688.

3. Qian ZR, Li T, Ter-Minassian M, et al. Association between somatostatin receptor expression and clinical outcomes in neuroendocrine tumors. Pancreas. 2016;45:1386-1393.

4. Caplin ME, Pavel M, Ćwikła JB, et al. Lanreotide in metastatic enteropancreatic neuroendocrine tumors. N Engl J Med. 2014;371:224-233.

5. Caplin ME, Pavel M, Ćwikła JB, et al. Anti-tumour effects of lanreotide for pancreatic and intestinal neuroendocrine tumours: The CLARINET openlabel extension study. Endocr Relat Cancer. 2016;23:191-199.

6. Vinik Al, Wolin EM, Liyanage N, et al. Evaluation of lanreotide depot/ autogel efficacy and safety as a carcinoid syndrome treatment (ELECT): A randomized, double-blind, placebo-controlled trial. Endocr Pract. 2016; 22:1068-1080.

7. Cives $M$, Strosberg J. The expanding role of somatostatin analogs in gastroenteropancreatic and lung neuroendocrine tumors. Drugs. 2015; 75:847-858.

8. Saif MW. Lanreotide for the treatment of gastroenteropancreatic neuroendocrine tumors. Expert Opin Pharmacother. 2016;17:443-456.

9. Sandostatin $L A{ }^{\circledR}$ Depot (Octreotide Acetate for Injectable Suspension). Novartis Pharmaceuticals Corp.: East Hanover, NJ, 2014.

10. Rinke A, Müller HH, Schade-Brittinger $\mathrm{C}$, et al. Placebo-controlled, doubleblind, prospective, randomized study on the effect of octreotide LAR in the control of tumor growth in patients with metastatic neuroendocrine midgut tumors: A report from the PROMID Study Group. J Clin Oncol. 2009;27:4656-4663.

11. Somatuline ${ }^{\circledR}$ Depot (lanreotide) Injection [Prescribing Information]. Ipsen Biopharmaceuticals, Inc.: Basking Ridge, NJ; 2017. 
12. Bajetta E, Procopio G, Catena L, et al. Lanreotide autogel every 6 weeks compared with Lanreotide microparticles every 3 weeks in patients with well differentiated neuroendocrine tumors: A Phase III Study. Cancer. 2006;107:2474-2481.

13. Bajetta E, Zilembo N, Di Bartolomeo M, et al. Treatment of metastatic carcinoids and other neuroendocrine tumors with recombinant interferon-alpha-2a. A study by the Italian Trials in Medical Oncology Group. Cancer. 1993;72:3099-3105.

14. Eisenhauer EA, Therasse $P$, Bogaerts J, et al. New response evaluation criteria in solid tumours: Revised RECIST guideline (version 1.1). Eur J Cancer. 2009;45:228-247.

15. Korse CM, Taal BG, Vincent A, et al. Choice of tumour markers in patients with neuroendocrine tumours is dependent on the histological grade. A marker study of Chromogranin A, Neuron specific enolase, Progastrinreleasing peptide and cytokeratin fragments. Eur J Cancer. 2012;48: 662-671.

16. Phan AT, Dasari A, Liyanage N, et al. Tumor response in the CLARINET study of lanreotide depot vs. placebo in patients with metastatic gastroenteropancreatic neuroendocrine tumors (GEP-NETs). J Clin Oncol. 2016;34:434-434.

17. Tang C, Gong L, Zou W, et al. Multivariate analysis of metastasisrelated risk factors for patients with gastroenteropancreatic neuroendocrine tumors based on clinicopathological and endoscopic features. Oncol Rep. 2016;36:3343-3352.

18. Buil-Bruna N, Dehez M, Manon A, et al. Establishing the quantitative relationship between lanreotide autogel ${ }^{\circledR}$, chromogranin $A$, and progression-free survival in patients with nonfunctioning gastroenteropancreatic neuroendocrine tumors. AAPS J. 2016;18:703-712.

19. Formica V, Wotherspoon A, Cunningham D, et al. The prognostic role of WHO classification, urinary 5-hydroxyindoleacetic acid and liver function tests in metastatic neuroendocrine carcinomas of the gastroenteropancreatic tract. Br J Cancer. 2007;96:1178-1182.

20. van der Horst-Schrivers AN, Post WJ, Kema IP, et al. Persistent low urinary excretion of 5-HIAA is a marker for favourable survival during follow-up in patients with disseminated midgut carcinoid tumours. Eur J Cancer. 2007; 43:2651-2657.
21. Zandee WT, Kamp K, van Adrichem RC, et al. Limited value for urinary 5HIAA excretion as prognostic marker in gastrointestinal neuroendocrine tumours. Eur J Endocrinol. 2016;175:361-366.

Cite this article as: Saif MW, Fu J, Smith MH, Weinstein B, Relias V, Daly KP (2018) Treatment with lanreotide depot following octreotide long-acting release among patients with gastroenteropancreatic neuroendocrine tumors, Journal of Pancreatic Cancer 4:1, 64-71, DOI: 10.1089/pancan.2018.0013.

$\quad$ Abbreviation Used
$5-\mathrm{HIAA}=$ 5-hydroxyindoleacetic acid
$\mathrm{AE}=$ adverse event
$\mathrm{CgA}=$ chromogranin $\mathrm{A}$
$\mathrm{Cl}=$ confidence interval
$\mathrm{CLARINET}=$ Controlled Study of Lanreotide Antiproliferative
$\mathrm{CR}=$ Response in Neuroendocrine Tumors
$\mathrm{FDA}=$ Food and Drug Administration
$\mathrm{GEP}-\mathrm{NETs}=$ gastroenteropancreatic neuroendocrine tumors
$\mathrm{LAR}=$ long-acting release
$\mathrm{MRI}=$ magnetic resonance imaging
$\mathrm{NETs}=$ neuroendocrine tumors
$\mathrm{PFS}=$ progression-free survival
$\mathrm{PR}=$ partial response
$\mathrm{SD}=$ stable disease
$\mathrm{SSAs}=$ somatostatin analogs
$\mathrm{Y}^{90} \mathrm{TARE}=$ yttrium-90 tranarterial radioembolization

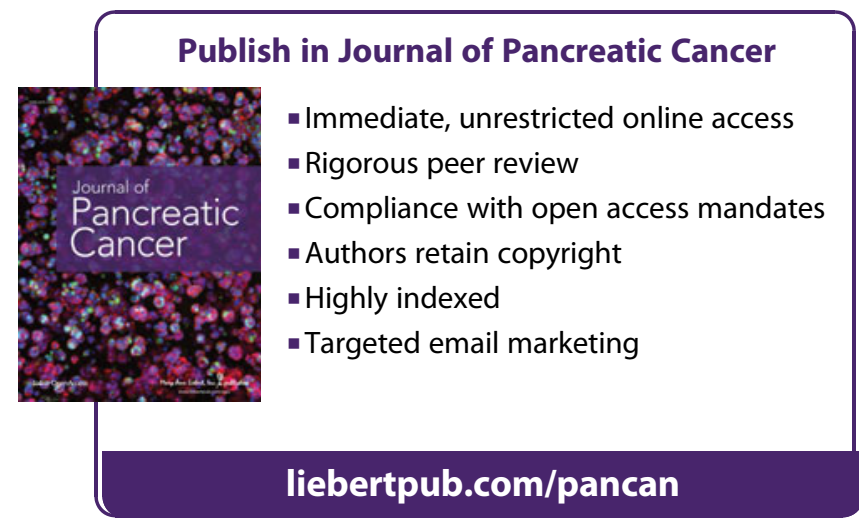

